\title{
A COMPATIBILIDAde da SOCIEDAde ABERTa E O ESTAdo DEMOCRÁtico de DIREITO COM A JUDICIALIZAÇÃO DA POLÍTICA
}

\author{
Compatibility of the open society and democratic state law with \\ judicialization policy
}

\section{Carlos Alberto Alves Ribeiro Filho}

Advogado; pós-graduação em Direito Tributário pelo IBET (Instituto Brasileiro de Estudos Tributários); Mestrando em Direito e Garantias Fundamentais - FDV (Faculdade de Direito de Vitória). E-mail: carlosalribeirofi@hotmail.com.

RECEBIDO EM: 27.07.2013

APROVADO EM: 15.01.2014

\section{Resumo}

Os anseios de uma sociedade aberta se refletem em sua Constituição como marco fundamental para uma sociedade justa. Os marcos primeiros relacionam-se com o estabelecimento de um Estado Democrático de Direito, em que a Democracia é efetivada. Discute-se a sociedade pretendida e seus reflexos nos direitos fundamentais. Uma sociedade aberta pressupõe o espaço para implementação dos direitos fundamentais. A democracia pretendida constitui o mote para o desenvolvimento das instituições. Entretanto, o Estado brasileiro, ante as desigualdades existentes, vê-se frequentemente acionado por seu Judiciário para solução de políticas publicas. Neste caso, cabe uma discussão quanto à forma de ser proferida uma decisão judicial e sua compatibilidade com a Constituição.

Palavras-chave: Sociedade aberta. Democracia. InterpretaÇão democrática.

\section{Abstract}

The desire for an open society is reflected in its constitution as a milestone for a just society. The milestones the 1st relate to the establishment of a democratic state, in which democracy is effected. It discusses the company intended and its effects on fundamental rights. An open society requires space for the implementation of fundamental rights. Democracy is the desired tone for the development of institu- 
tions. However, the Brazilian state, compared to the existing inequalities, it is often seen driven by their judiciary to solve public policy. In this case, it is a discussion about how to render a judicial decision and its compatibility with the Constitution.

Keywords: Open SOCIETy. Democracy. Democratic InTERPRETATION.

SumáRIo: Introdução. 1. Sociedade aberta. 2. O estado de direito. 2.1. Aspectos da democracia. 3. Judicialização da política. 3.1. Interpretação democrática. 3.2. Dos direitos fundamentais sociais. 3.3. A sociedade aberta como parâmetro. Conclusão. Referências.

\section{INTRODUÇ̃̃o}

Promover o debate da judicialização da política, contextualizando com a sociedade moderna e ainda mediante a realidade ditada pela Constituição da República do Brasil. A Democracia como base do porvir do Estado de Direito.

A "sociedade aberta", expressão cunhada por Karl Popper, repercute como base para o diálogo necessário no interior de um Estado e ainda mais para um mundo globalizado, de forma econômica, tecnológica, e tantos outros efeitos da globalização. O certo é que não se imagina um mundo fundado em um Estado totalitário.

$\mathrm{Na}$ sociedade atual, a base é democrática, a linguagem entre os povos é direta por Convenções, Tratados ou Acordos internacionais sejam eles bilaterais ou de formação de mercados.

Karl Popper estabelece o falibilismo como método, em que a busca pela verdade é feita por refutações, e que os dogmas, neste contexto servem ao poder, assim como a linguagem hermética, hergeliana ou de seus seguidores. A influência traduz no diálogo e no debate democrático, estabelecido por meio de teses e argumentos científicos, para tanto, o aprofundamento pode ser realizado nas obras: "A logica das ciências sócias" e "Conjecturas e Refutações" do referido Autor.

O Estado de direito foi apresentado já no período moderno, em que o Constitucionalismo pode sofrer mudanças de acordo com o Estado, percebe-se o quanto é cara a integração social, a cidadania de imigrantes e que também a visão pode ser invertida dentro do próprio Estado Democrático de Direito, bastando, para tanto, a troca de referencial. Respeita-se a decisão de uma maioria, sem perceber que o Estado de Direito, possui uma postura democrática como "auto-governo" e como "auto-realização", desde que se implemente ou vigore um Estado que valoriza o indivíduo ou grupos, sendo certo que a direção provocada leva a busca por governo e realização individual democráticos.

Portanto, haveria a compatibilidade de uma sociedade aberta e o Estado 
Democrático de Direito com a judicialização da política?

Vê-se que a judicialização da política, é um fenômeno novo no judiciário do Estado Brasileiro, em que se deve levar em consideração o teor da Constituição Nacional, a sistematização da política, os fundamentos do Estado, objetivos, direitos e garantias fundamentais.

Por fim, a proposição de uma "nova hermenêutica", a partir de Peter Haberle, visa aplainar o que pode ser considerado "judicialização da política", posto que por uma via democrática de interpretação o judiciário poderia estabelecer um contato maior com a sociedade e seus interesses, quebrando o monopólio de intérpretes da Constituição. Para tanto, importante considerar a "Sociedade Aberta" e democrática.

\section{Sociedade ABERTA}

Após a $2^{\mathrm{a}}$ Guerra Mundial, restou evidente para o mundo as conseqüências trágicas dos Estados Totalitários, sejam eles Nazistas ou ditos “Comunistas". A Democracia e a liberdade de expressão foram temas recorrentes, para tanto, Karl Popper em sua obra a Sociedade Aberta e seus inimigos, delineou a origem filosófica, ou matrizes teóricas destes regimes totalitários.

Para Karl Popper "Os homens buscam expandir sua liberdade: buscam novas possibilidades" (2006, p.26). Destaca que a competição contribui para este processo, onde novas possibilidades de subsistência e de vida para construção de "novos nichos: ecológicos e para o indivíduo. Podemos questionar o que seria mais interessante para uma interpretação da sociedade: "a restrição da liberdade" ou a "expansão da liberdade", podem ser considerados caminhos simplistas, mas conduzem a "verdades".

Por consequência o próprio Popper já indicava:

[...] O grande sucesso da sociedade competitiva e a grande ampliação da liberdade a que tal sociedade conduziu são explicados apenas pela interpretação otimista. Ela é a melhor interpretação: aproxima-se mais da verdade, explica mais (POPPER, 2006, p. 26).

Pode-se ainda apontar uma "ideologia pessimista" como interprete de que ocorre a adaptação da vida ao ambiente, em que tudo surge pela luta de uns contra os outros e contra a natureza, a saber, uma luta cega. Por outro aspecto, para uma "nova ideologia" fundada no que se pode chamar de uma interpretação otimista, tem-se a mudança de ponto de vista estabelecida, por exemplo, na busca por melhores ambientes e por um mundo melhor, tendo como método a tentativa e eliminação de erros. (POPPER, 2006, pp. 29-32).

Neste aspecto, como nexo de causalidade, a linguagem se apresenta como canal de possibilidades, ainda mais pela "crítica", "escolha consciente de teorias", 
se apropriando de proposições verdadeiras ou falsas, busca-se a seleção crítica, de forma cultural, em que se procura ultrapassar os erros de forma consciente, sendo ponto incisivo para Karl Popper: "Não há conhecimento sem crítica racional, crítica a serviço da busca da verdade", relacionado com o conhecimento científico (POPPER, 2006, pp. 38-39).

O emprego da crítica consciente e dos métodos da crítica racional, podem levar "A formação de nosso ambiente social com o objetivo da paz e não da violência não é apenas um sonho. É meta possível e, do ponto de vista biológico, obviamente necessária para a humanidade" (2006, p. 49).

O Estado a partir da $2^{\mathrm{a}}$ Guerra alcançou outras vertentes, fruto das experiências traumáticas geradas por regimes totalitários, tomando o rumo de aberta ao diálogo, para tanto, a Europa enveredou pelo Estado Providência, como forma de recuperar e criar condições para minimizar desigualdades, estabelecendo uma rede de proteção social, era o momento maior da social democracia. Realmente, o Estado intervencionista, ampliou suas bases burocráticas, não conseguindo arcar com os custos de políticas sociais. Por outro lado, aproximou cidadãos diminuindo a distância entre pobres e ricos, na mesma sociedade, sem deixar de atender as aspirações de liberdade de expressão, prática da sociedade aberta.

O Estado de Bem-Estar Social, ou Estado Intervencionista, ou ainda o "Welfare State", como é comumente conhecido, nasceu no pós guerra, também pelo não atendimento das expectativas de igualdade e fraternidade, o que acabou incorporando ao Estado a preocupação social como oposição à exacerbada proteção da liberdade. Assim, desta postura intervencionista, a social democracia, o Estado passou a agir diretamente para atender alguns direitos básicos dos trabalhadores, como educação, assistência social, trabalho, etc., gerando preocupações com os chamados direitos sociais.

Não se pretendia um Estado puramente liberal, bem como foi superado a ideia de um estado provedor, contudo, os direitos sociais, constituem pilar para o equilíbrio: saúde, assistência social, trabalho, tem sido distribuída, por assim dizer, com a participação da sociedade civil e não mais exclusivamente pelo Estado, modificando ou aprofundando a relação entre o público e o privado, no campo de atuação das políticas sociais, uma vez que tal obrigação deixa de ser exclusiva do Estado, pois vem sendo descentralizado para os entes privados, muito embora no Brasil, estes custos têm sido exigidos de forma "dobrada", recolhe-se o tributo para o Estado, e ainda são exigidos serviços complementares privados, podendo-se dizer sobre um sistema misto.

Portanto, dos limites entre o público e o privado devem ser estipulados por um processo democrático, definindo-se as bases que garantam liberdades a todos os cidadãos, "[...] sob as formas tanto da autonomia privada quanto da autonomia pública" (HABERMAS, 2007, p. 38).

Daí, a globalização, a partir dos anos 90 do século passado, veio estabele- 
cer novas bases na relação entre os Estados, bem como internamente, modificando a ideia de "Estado nacional", entretanto, pode-se destacar, especialmente na Europa, o trânsito, comunicação, produção econômica, e de seu financiamento, da transferência de tecnologia, poderio bélico, riscos militares e ecológicos, os quais suplantam a capacidade dos Estados resolverem no âmbito nacional, mas a partir destas novas perspectivas esvazia-se o conceito de soberania de Estados nacionais, voltando-se para busca de soluções de alcance supranacional.

O Estado moderno atual, esta direcionado a tarefas, essencialmente, administrativas, abandonando a produção efetiva, passando a estabelecer condições gerais de produção, tais como legislação, organização do trabalho, tendo como base a captação de impostos da iniciativa privada, "[...] para o processo de modernização é a separação do Estado da "sociedade civil", ou seja, a especificação funcional do aparato estatal" (HABERMAS, 2007, p. 131).

Interessante analisar como contraponto à globalização econômica, as consequências sociais, cada vez mais impostas em decisões, as quais possuem caráter supranacional. Ocorre um deslocamento de possibilidades em que os Estados deixam de atuar de forma incisiva na dinâmica produtiva, passando a deliberar medidas administrativas. Contudo, o choque social é previsível e Boaventura Sousa Santos alerta para o que chamou de fascismo social:

[...] é um conjunto de processos sociais mediante os quais grandes sectores da população são irreversivelmente mantidos no exterior ou expulsos de qualquer tipo de contrato social.

Grande margem à exclusão social - subclasses, não é o Estado que poderá se tornar fascista mais sim as relações - locais - nacionais e internacionais (2008, p. 192).

Os aspectos levantados por Boaventura de Sousa Santos se comprovam, verificando-se que não existem políticas de inclusão para todos, isto na grande maioria dos Estados, em que os próprios cidadãos deixam de se indignar, expressar "rebeldia", adequando-se a estrutura, conformada pelo que chamou de "globalização hegemônica": "[...] o fascismo social é pluralista, coexistente facilmente com o Estado democrático e o seu espaço-tempo privilegiado, em vez de ser nacional, é simultaneamente local e global" (2008, p. 192).

A solução para este dilema estaria na capacidade de se indignar, mudar o enfoque de que o futuro ser melhor, nada se aprende com o passado senão a confiar no futuro, entretanto, propõe:

[...] é preciso, pois, lutar por uma outra concepção de passado, em que este se converta em razão da nossa raiva e do nosso inconformismo. Em vez do passado neutralizado, o passado como perda irreparável resultante de iniciativas humanas que muitas vezes puderam escolher entre alternativas. (SANTOS, 2008, pp. 82-83). 
Por outro lado, a sociedade aberta pressupõe diálogo permanente, entre as diferenças, mediante os princípios da "discussão racional", falibilidade e aproximação da verdade (POPPER, 2006, p. 257). Mesmo as mais modernas teorias, que propõem o multiculturalismo, estão inseridas nesta sociedade, posto que, do contrário seriam uma sociedade fatiada, "tribal".

Cabe ainda a observação quanto "a imagem do ser humano dentro do Estado Constitucional”, exposta por Peter Haberle, em que afirma:

El concepto jurídico de la imagem del ser humano, de este modo, se mantiene abierto y, gracias a los derechos fundamentales, es revisable, de modo que pueda assumir paulatinamente los contenidos transformados y puede deshacerse gradualmente de los antigos (HABERLE, 2001, p. 132).

A imagem concreta do ser humano advém dos direitos fundamentais: dignidade da pessoa humana, liberdade, igualdade, tolerância, justiça, paz etc., bem como a própria defesa dos direitos humanos, como conteúdo para a formação de um conceito, que se propõe aberto, em que "o racionalismo crítico", constitui maneira importante para questionar dentro de uma perspectiva plural (HABERLE, 2001, p. 132).

Este conceito é construído a partir da realidade constitucional, em princípios expostos ao longo do texto constitucional, como retro mencionado, em que "[...] la imagen del ser humano y la imagen del Estado Constitucional corresponden a una unidad" (2001, p. 65).

Assim, a Constituição é o foco principal, das bases instituidoras do Estado Democrático de Direito, assim, como marco para a "sociedade" brasileira, desde o preâmbulo, estes ajustes são demonstrados: “[...] instituir um Estado Democrático, destinado a assegurar o exercício dos direitos sociais e individuais, a liberdade, a segurança, o bem-estar, o desenvolvimento, a igualdade e a justiça [...]", sendo que a seguir declara que estes são valores "supremo" de uma sociedade que anuncia ser "[...] pluralista e sem preconceitos [...]".

Além disso, os Títulos I e II da Constituição do Brasil estabelecem fundamentos, objetivos, direitos e garantias fundamentais (individuais e coletivos), os direitos sociais, nacionalidade, direitos políticos e sobre partidos políticos. O "Estado Democrático de Direito" brasileiro se inaugura por assim dizer nos "princípios fundamentais, estando relacionado seus fundamentos, objetivos e até a forma de se praticar relações internacionais. Outros aspectos fundamentais declarados e que podem ser destacados, se referem aos direitos e deveres individuais e coletivos, bem como os direitos sociais.

Desta forma, os "interesses" da sociedade brasileira, estariam permeados nos Títulos I e II da Constituição da República, servindo de direcionamento para os cidadãos, por conseguinte, poderiam ser objeto, de maior divulgação para sociedade, 
destacados, publicados e distribuídos, não se trata de fatiar a Constituição, mas uma opção para exposição.

\section{O ESTADO DE DIREITO}

Os Estados modernos, especialmente pós $2^{\mathrm{a}}$ Guerra Mundial se moldaram a partir da Constituição, estabelecida levando em conta o pluralismo "[...] o constitucionalismo moderno requer o governo limitado, aceitação da rule of law, ou seja do Estado de Direito, e a proteção dos direitos fundamentais" (ROSENFELD, 2003, p. 36).

Esta limitação do governo pelo constitucionalismo se dá priorizando ou valorando alguns aspectos, de acordo com a vontade dos "constituintes", mudando de enfoque de acordo com cada país, para tanto importante observar como exemplo o que foi estabelecido pelos norte-americanos e franceses, sendo assim importante destacar que ainda Michel Rosenfeld diz que nos Estados Unidos havia o entendimento por uma limitação do governo realizada por uma distribuição de poderes entre os respectivos entes: Estadual e Federal (2003, p.37).

O mesmo Autor ressalta a necessidade do controle político e supervisão em que a não efetivação, neste caso a função primordial do que foi instituído no sistema dos Estados Unidos os "freios e contra-pesos", configurando a divisão de poderes (2003, p. 37).

Diferenciando do modelo norte-americano, a Constituição francesa de 1793, está calcada na supremacia do legislativo, em que a vontade geral deve ser respeitada conforme preceitos de Rousseau, em que a "[...] a vontade geral é a soma das diferenças entre as vontades individuais [...]” (2003, p. 39).

Após a $2^{\text {a }}$ Guerra, os países organizados, rejeitaram os modelos totalitários ou ditatoriais, frutos dos traumas gerados por governos que buscavam o controle total político, tais como o "Nazismo", "Fascismo" e até mesmo o "comunismo soviético", sendo este modelo esgotado em 1989, com a queda do muro de Berlim.

Neste sentido, depreende-se que os limites normativos ao constitucionalismo, decorrem da proteção do Estado do poder político totalitário, o que seria o compromisso com o princípio do governo limitado, a adoção do princípio do Estado de Direito e a proteção dos direitos fundamentais.

Deve-se perceber que o Estado de direito numa democracia "[...] é a expressão da vontade da maioria, por um lado, e, por outro lado, uma coerção, porque, se eu estou numa minoria legislativa e a lei é aplicada contra mim, é o poder do Estado contra mim, e porque as maiorias legislativas mudam" (ROSENFELD, 2004, pp. 13-14).

Claro está que o Estado de Direito se baseia em leis, e não na vontade de um "soberano", neste sentido a democracia agrega a vontade da maioria, debatidas e decididas no Parlamento, de acordo com cada sociedade, cada país, assim "[...] o 
Estado de Direito é uma ordem política em que o governo é feito por meio de leis e não de acordo com a vontade do soberano ou de decretos [...]" (2004, p. 13).

Mediante vontade popular e processos de escolha podem ocorrer "[...] A exclusão social da população de um Estado resulta de circunstâncias históricas que são externas ao sistema dos direitos e aos princípios do Estado de direito" (HABERMAS, 2007, p. 254).

Isto decorrente de processo cultural e modo de vida próprios, em que não ocorre um reconhecimento ou inclusão do outro, mas a pressão imigratória e associações voluntárias, causam a modificação do contexto, do modus vivendi.

Júrgen Habermas na obra "A inclusão do Outro", anotou a questão da "imigração, cidadania e identidade constitucional", inserido no Estado democrático de direito, e problematização da questão, especialmente vigente no Estado Alemão, até meados dos anos noventa do século passado - período de lançamento da primeira edição alemã.

Verifica-se então segundo Jurgem Habermas que existem vários grupos étnicos, imigrantes residentes na Alemanha, os quais não possuem cidadania, e não estão integrados, "[...] o teor ético de uma integração política que unifique todos os cidadãos precisa ser "neutro" em face das diferenças que haja no interior do Estado entre comunidades ético-culturais que se integram cada qual em torno de uma respectiva concepção própria do que seja o bem" (2007, p. 265).

Pode-se entender que a sociedade aberta pode ser ameaçada, pondo em cheque o Estado democrático de direito, dada a afluência de imigrantes, os quais podem descaracterizar uma população de um país:

Isso explica a questão quanto aos limites do anseio por imigração: ele não esbarra justamente no direito de uma coletividade política a manter inata sua forma de vida político-cultural? E o direito à autodeterminação - sob a premissa de que a ordem geral do Estado, conformada de maneira autônoma, está eticamente impregnada - não inclui o direito à auto-afirmação da identidade de uma nação? E isso também diante de imigrantes, que poderiam alterar a índole amadurecida ao longo da história de uma forma de vida político-cultural? (HABERMAS, 2007, p. 265).

Vê-se então, que o debate quanto à naturalização de imigrantes possui uma conotação interessante, ainda mais no que se refere aos reflexos quanto aos direitos à cidadania, em que haveria de ocorrer assimilação de culturas.

Neste particular Jurgen Habermas altera a ótica, ou seja, passa questionar se o Estado democrático de direito teria como impor ao imigrante tal assimilação, sendo que o caso é justamente inverso, o direito de ser natural, ainda mais estando em um Estado há mais de trinta anos.

Evidencia-se a dificuldade do Estado Alemão em conceder naturalização e 
cidadania, sendo que no final do século XIX e início do século XX, devido as guerras, o processo de saída de alemães por falta de oportunidades foi intensa, reconhecendo que nacionalismo alemão tenha surgido de um “'[...] caráter único e peculiar da cultura e ascendência étnica além-alemã - um particularismo que marcou de forma duradoura a autocompreensão desse povo" (2007, pp. 271-273).

\subsection{Aspectos DA DEMOCRACIA}

Quando se trata democracia, deve-se ter a percepção de liberdade, a atuação privada e pública: "[...] as liberdades de ação individuais do sujeito privado e a autonomia pública do cidadão ligado ao Estado possibilitam-se reciprocamente" (HABERMAS, 2007, 298).

E esta liberdade e suas nuances, coletivas e individuais, são expressas como em campo na Constituição de cada país e Michel Rosenfeld em Conferência proferida em Belo Horizonte no ano de 2003, traduziu a ideia de "constitucionalismo", em que cada país possui sua característica, baseados no Estado de Direito, havendo graduações ou formas de controle do poder político, entretanto, a democracia agrega valor, entendendo que seja "[...] boa, mas ela é perigosa. A maior preocupação de Madison, que era uma das maiores forças intelectuais por trás da Constituição americana era o medo da tirania da maioria" (ROSENFELD, 2004, p. 17).

Sendo esta, a característica para cada nação representada pelo respectivo Estado. E o poder democrático exercido de forma desconcentrada, desta forma a ideia dos Estados federados e divisão dos Poderes (2004, p. 18).

Desta forma, ao contrário do que se pode perceber "[...] Estado de Direito, em si mesmo, não tem nada a ver com democracia [...]” (2004, p. 18), colocação esta que se agrega ao modelo de constitucionalismo de cada Estado.

Por exemplo, o Estado francês, Nelson Rosenfeld percebeu o equívoco cometido por muitos em considerar " [...] o chamado.L.état de Droit., que é comumente dado como equivalente [...]", ao "Rule of Law" (2004, p. 19).

Entretanto, a ideia de Reichtstaat não tem mesmo significado paro o que se convencionou chamar L.état de Droit., para tanto a Revolução Francesa cunhou na verdade o "Estado Legal", Létat Légal:

Estado Legal; eu traduzi isso, no inglês, como o Estado por meio da democracia jurídica, o Estado por meio da regra democrática, da lei democrática, com a soberania do Parlamento e a pressuposição de que a criação legislativa só é legítima por meio da democracia. Os franceses instituíram um regime legal que é um regime democrático. Na França, a maioria comanda, é uma maioria nacional, é um Estado centralizado, unificado. $\mathrm{O}$ governo da maioria do povo francês, por meio do Poder Legislativo, do Parlamento, comanda, cria suas leis. O .L.état Légal. é a realização, na 
esfera política, de uma idéia de Jean-Jacques Rousseau, da democracia que resulta da implementação da vontade geral (2004, pp. 19-20).

Por conseguinte, "[...] a submissão ao direito, seja ao direito constitucional ou ao direito comum, geralmente é sentida como impositiva. Eu tenho que seguir a lei de alguém que impõe essa lei a mim. E o Estado de Direito tem essa dupla conotação [...]" (2004, p. 20).

Evidente que o juiz da "Common Law", possui um poder normativo traduzindo para o cidadão a aparência de uma auto regulamentação e uma regulamentação imposta, devido a este papel único do juiz.

Michel Rosenfeld indica a convivência entre "democracia Constitucional e a Comum", como esferas de interesses, em que "[...] a democracia comum, em que as pessoas lutam pelos seus interesses: alguns querem mais produção, outros, um meio ambiente melhor, $[\ldots]$ " e ainda por "[...] leis que gerem mais empregos, pois é para isso que lutam as pessoas que constituem a maioria" (2004, p. 25).

No que se refere à democracia constitucional o Autor acima mencionado, remonta a diferença entre uma democracia constitucional e uma democracia comum, como "[...] as noções de que um povo que se auto-governo precisa de propósitos para operar como tal, nós podemos olhar isso como envolvendo a ordem da democracia constitucional, e olhar o que não faz parte disso como democracia comum, ordinária [...]" (2004, p. 26).

Neste sentido, o constitucionalismo poderá variar para cada país, por seu histórico, tradição, cultura, enfim sua "identidade constitucional". Baseando-se numa sociedade pluralista.

O exemplo traçado por Rosenfeld é interessante, pois caracteriza o que chamou de "auto-governo" e "auto-realização", e os meandros de intercessão:

Numa sociedade pluralista, há o problema do reconhecimento, que é, em resumo, o de que todos os indivíduos e todos os grupos devem ser levados em consideração. Esse é um problema de auto-governo se você quer democracia. Por que queremos a democracia? Porque, se você reconhece o povo, você deve dar a ele uma chance de participar da realização de seu próprio destino (ROSENFELD, 2004, p. 26).

A "auto-realização" encontra-se em um nível individual ou a um nível comunitário, desta forma uma maioria pode não concordar, e por outro aspecto deve participar ou ser reconhecido, em busca da "auto-realização", por isto a Constituição, na democracia constitucional permite ou possui mecanismos para implementação. Por outro lado, é importante uma política estabelecida para respeitar direitos, como medida de autogoverno.

Por fim, a partir do "auto-governo", que cria dispositivos em respeito a 
grupos existentes numa sociedade pluralista, deve partir de uma concepção de constitucionalismo possuindo elementos que limitam o governo, de submissão ao Estado de Direito, além da proteção aos direitos fundamentais (2004, p. 27).

Pode-se buscar então uma "construção do sujeito constitucional", que deve ser aprofundado pelo convívio na comunidade, em busca da dignidade,

[...] a Constituição pode ser considerada o pano de fundo moral para o reconhecimento da cidadania, ou seja, ela deve não só pautar toda a atuação do estado, como também o agir social, pois sem esse ethos valorativo mínimo, ou seja, sem o reconhecimento ético da identidade cidadã não há propagação suficiente do sentimento constitucional (MOREIRA, 2010, pp. 201-202).

Tanto a busca da "auto-realização" e do "autogoverno", propostos por Rosenfeld, não divergem da "construção do sujeito constitucional", uma vez que o objetivo é partir de uma consciência de cidadania.

\section{Judicialização da POlítica}

Na conferência proferida Zurique, 1958, sob o título "Em que acredita o Ocidente?", Karl Popper lançava questionamentos críticos sobre a estrutura básica do mundo pós- 2 a Guerra, expondo, já naquela época: "Se não conseguimos tornar a pobreza uma raridade, poderemos facilmente perder nossa liberdade para a burocracia do Estado de bem-estar social.” (2006, p. 282)

O Autor tece considerações fortes sobre a chamada "economia planifica", vigente na antiga União Soviética, adotando, para tanto, uma visão baseada na economia de mercado livre, como opção preferencial, posto que, "[...] seria contra a economia planificada; simplesmente porque ela amplia o poder do Estado até a tirania." (2006, p. 283)

A política pode ser um campo de combate, e o que se propõe pode ter diversas conotações, seria o caso de se estabelecer prioridades: “[...] não é a ineficiência econômica que combatemos: é a sua falta de liberdade e humanidade." (2006, p. 283)

Logo na abertura da conferência acima referenciada, Karl Popper, de forma irônica desfere critica o hegelianismo e ao historicismo, colocando-os como fundadores do autoritarismo, referindo-se a Schopenhauer como quem "[...] há mais de cem anos desmascarou, combateu como peste intelectual da Alemanha", (2006, p. 283) o pensamento de Hegel.

As críticas do filósofo Schopenhauer, contemporâneo de Hegel, foram diretas: 
Hegel, imposto de cima pelos poderes vigentes como o Grande Filósofo oficializado, era um charlatão de cérebro estrito, insípido, nauseante, ignorante, que alcançou o pináculo da audácia por garatujar e forjicar as mais malucas e mistificantes tolices. Essas tolices foram barulhentamente proclamadas como uma sabedoria imortal, por seguidores mercenários, e prontamente aceitas como tal por todos os tolos, que assim se juntaram num coro perfeito de admiração, como nunca antes se ouvira (POPPER, 1998, p. 39).

Ao questionar Platão como teórico da forma de governo absolutista e dos regimes totalitários, cabe destacar o enfoque:

Ele põe como problema fundamental da teoria do Estado a seguinte pergunta: "Quem deve governar? Quem deve reger o Estado? Os muitos, a multidão, a massa ou os poucos, os eleitos, a elite? (POPPER, 2006, p. 283).

Decorre que para Platão, a pergunta “quem deve governar"? A resposta estaria direcionada aos melhores da aristocracia. Para Popper a pergunta fundamental da teoria do Estado teria outra conotação

[...] Não é “Quem deve governar?” ou Quem dever ter o poder?” mas "Quanto poder se deve conceder ao governo?" ou talvez de modo mais preciso: "Como podemos construir nossas instituições políticas de tal modo que até mesmo governantes incompetentes e desonestos não tenham como causar grande dano?”. (2006, p. 284).

O problema fundamental da teoria do Estado, para Karl Popper, estaria no que ele abordou como "domesticação" do poder político, em relação a arbitrariedade e do abuso de poder, calcado por instituições em que este poder seja dividido e controlado (2006, p. 284).

O raciocínio de Karl Popper constitui algo prático e aponta uma direção clara em que permeia sua obra, especialmente a busca por soluções, posto que sabemos que a Democracia não é o melhor dos mundo, mas o possível: "[...] existem apenas duas formas de governo: aquela que permite aos governados se livrar de seus governantes sem derramamento de sangue, e aquela que não lhes permite isso, ou apenas com derramamento de sangue" (POPPER, 2006, pp. 284-285).

Em decorrência desta forma de pensar o Autor rememora o Estadista Wiston Churcil, em que para ele "[...] A democracia é a pior de todas as formas de governo, com exceção de todas as outras formas de governo" (2006, p. 285).

Realmente, o voto é a única forma de produzir decisões sem derramamento 
de sangue, e o mínimo de restrição à liberdade: "E insistimos em que as minorias têm seus direitos de liberdade, que jamais podem ser eliminados pela decisão majoritária" (2006, p. 286).

A democracia perdura, mesmo superado o Estado de bem-estar social, especialmente, como intervencionista, se percebe a Constituição da República do Brasil, possui este viés, digamos, integracionista e inclusivo, sem perder a ótica, liberal, uma vez que protege direitos individuais. Resta inserir as políticas públicas como uma das funções do Estado, no sentido de condução de inclusão e concretização dos direitos sociais.

Para Maria Paula Bucci "O fundamento mediato das políticas públicas, o que justifica o seu aparecimento, é a própria existência dos direitos sociais - aqueles, dentre o rol de direitos fundamentais do homem, que se concretizam por meio de prestações positivas do Estado" (BUCCI, 1996, p. 135).

Como direito de segunda geração os direitos fundamentais sociais são realizados se forem impostos por obrigações positivas. Por consequência estabelece-se uma maior necessidade de ações específicas do Estado, no sentido de apontar caminhos de iniciativa pública e privada.

Existem outras políticas que se coadunam como politicas setoriais, inseridas numa política de desenvolvimento como um todo do país, tais como: a política industrial, a política de transportes, entre outras.

Portanto, as políticas públicas podem ser insertas como "[...] programas de ação do governo, para a realização de objetivos determinados, num espaço de tempo certo.” (BUCCI, 1996, 140) As políticas públicas podem estar inseridas no plano de governo, sente este a expressão maior, fundado na lei que estabelece metas, objetivos, instrumentos de realização e outras formas de implementação (BUCCI, 1996, p.140).

Ada Pellegrini Grinover em seu Artigo “o controle de políticas públicas pelo poder judiciário", transcreve o conceito de Oswaldo Canela Júnior:

Por política estatal - ou políticas públicas - entende-se o conjunto de atividades do Estado tendentes a seus fins, de acordo com metas a serem atingidas. Trata-se de um conjunto de normas (Poder Legislativo), atos (Poder Executivo) e decisões (Poder Judiciário) que visam à realização dos fins primordiais do Estado (2009, p. 39).

Alerta ainda Maria Paula Bucci, como origem da política pública “[...] mesmo que resulte da iniciativa legislativa do governo, Poder Executivo, é o Poder Legislativo." Existem políticas que partem dos ditos programas de ação, por exemplo: programa do álcool, material escolar, em que são detalhados pelo Executivo, por formas normativas infra-legais, as quais constituem meios para a execução em que a função normativa da administraçãon(1996, p. 141). 
Importante ressaltar o paralelismo entre o processo de formulação de políticas públicas e atividade de planejamento. Deve ser acrescido que "A formulação de políticas consistiria, portanto, num procedimento e poder-se-ia conceituar, genericamente, os programas de ação do governo como atos complexos" (1996, p. 141).

Partindo daí o entendimento, o qual justifica o estudo das políticas públicas dentro do direito administrativo. Muito embora seja o Estado quem direcione as políticas públicas, fato é que em Países de tradição liberal como os Estados Unidos da América, a relação entre e o direcionamento de verbas destinadas a doação por particulares é muito alta e evidenciada, existindo também no Brasil, com menor tradição, entretanto, possui destinação social, não havendo um controle político, posto que, constitui altruísmo particular.

Deve-se, portanto, levar em consideração pontos norteadores da nossa sociedade inseridos na Constituição, os quais levam a judicialização de políticas, como as diferenças entre as classes sociais, a corrupção generalizada no poder, entretanto a judicialização da política, decorre do Estado Social proposto na Constituição.

Peter Häberle, na obra "Hermenêutica Constitucional: A sociedade aberta dos intérpretes da Constituição: contribuição para a interpretação pluralista e "procedimental" da Constituição", o estudo a respeito dos participantes da interpretação constitucional pode ser como esquecido pela Ciência Jurídica, voltando-se basicamente aos métodos da interpretação (1997, p. 12).

Por consequência, a partir de seu posicionamento deflui a compreensão de que os avanços não acompanharam a democratização da hermenêutica constitucional.

A integridade do Direito, como pacificação só por ele não basta, muito mais promover inclusão e integração social, mas a expectativa de comportamento, pode gerar equilíbrio, mesmo quando descumprida a norma (COURA, 2009, p. 203).

Então, a proposta de Peter Haberle se adequa, ante a possibilidade de um tratamento "hermenêutico" diferenciado, em que os interpretes seriam ampliados, tendo em vista a destinação das normas e as expectativas geradas.

Neste sentido, se o Estado é regido por uma Constituição, os cidadãos que tem sua vida determinada por esta, também se constitui legítimo intérprete (1997, p. 16). Ato contínuo, Peter Häberle propõe a construção de uma teoria democrática da interpretação constitucional, como destino diverso quando comparada à teoria jurídica tradicional, deixando evidente que a "palavra final" no que concerne a interpretação continua a ser do Tribunal Superior, entretanto, os indivíduos, os grupos de interesses e a "opinião pública democrática" cumprem o papel de "pré-intérpretes", "intérpretes indiretos ou a longo prazo" (1997, pp. 24-25).

A proposição de Peter Haberle se coaduna ao direito, mormente quando se tem em pauta os direitos e garantias fundamentais sociais, e ainda mais no país em que se necessita de maior controle democrático de decisões judiciais, quando se trata de políticas públicas, propondo uma Ciência Jurídica que leve em conta a realidade, 
quebrando, por assim dizer o monopólio do conhecimento válido a respeito dos textos normativos.

Cabe destacar, em primeiro plano, a importância da interpretação das normas de direitos fundamentais por seus destinatários específicos, como segundo a verificação de grupos de pressão: a repercussão social, quanto à decisão do magistrado, como forma de análise, crises e discussões que possam manter posicionamento inserido no contexto, voltado para uma sociedade democrática e plural, levando em consideração outras forças da esfera pública que contribuem para a construção da norma geral (1997, pp. 32-33).

Não se trata de elevar o "superego" do judiciário, ou do Supremo Tribunal Federal, mesmo porque segundo o Artigo de Ingeborg Maus, o grau de confiabilidade repercute na sociedade com aumentos de índices nas pesquisas de opinião, mas poderia ser um caminho novo para o judiciário brasileiro. Na Alemanha de 1987, data das pesquisas de opinião referenciadas no Artigo mencionado, o crescimento da imagem do judiciário não se deveu a apenas ao aumento das funções do judiciário, para que seja considerado como tal, além da disposição para litigar ou, o aumento do controle judicial sobre o legislador, não são fatos isolados "[...] acompanha essa evolução uma representação da Justiça por parte da população que ganha contornos de veneração religiosa" (MAUS, 2000, p. 185).

Para tanto, as referências a esta parte do texto expressam em $62 \%$ o índice de aprovação pública para o "Tribunal Constitucional" da Alemanha, em grau de confiança, naquela época.

\subsection{INTERPRETAÇÃO DEMOCRÁTICA}

O problema apresentado por Peter Harbele, segue uma visão democrática, ou para uma interpretação constitucional democrática, isto se constata nos títulos iniciais da Constituição da República do Brasil sob seus fundamentos, objetivos, direitos e garantias fundamentais, direitos sociais e coletivos., como exemplo justamente, de uma sociedade aberta, plural.

Discute-se a tempos a destinação das normas, mormente a legitimidade do texto normativo, quanto ao atendimento e as expectativas dos grupos sociais diretamente interessados em sua incidência. Perter Haberle defende, uma autêntica democratização da sociedade, para tanto, o dogma da linguagem deve ser quebrado, e isto é bem popperiano, posto que o dogma se põe a serviço poder, assim como a linguagem e seu uso exclusivo.

As obras de Peter Häberle estão permeadas do pensamento de Popper, também na "La Imagem del ser Humano dentro del Estado Constitucional", a ideia de uma "Sociedade Aberta" é defendida e contextualizada.

A base do pensamento de Karl Popper encontra-se no desenvolvimento do racionalismo crítico, bem como para a ciência o "falibilismo", em que a busca pela 
verdade leva a um conjunto de explicações imperfeitas sobre a realidade, que devem ser submetidas a testes contínuos e cada vez mais rigorosos, que levarão, cedo ou tarde, à sua superação.

O método científico para Karl Popper consiste na formulação de hipóteses acerca de problemas do conhecimento, a ser submetidos à crítica aplicando uma série de refutações, entendendo que a ciência: para poder ser qualificada de científica, deve ser desmentida por certos acontecimentos, o que sofrer maior aprofundamento nas obras: "Lógica das Ciências Sociais" e "Conjecturas e Refutações".

A sociedade aberta fundada na democracia, constitui um mal menor, posto que deve estar voltada para o diálogo, a crítica, sendo o oposto de "sociedades tribais", fechada, e sujeitas ao totalitarismo, sendo este o mote de sua obra Política, a denúncia dos regimes autoritários e totalitários .

\subsection{DOS DIREITOS FUNDAMENTAIS SOCIAIS}

$\mathrm{O}$ art. $6^{\circ}$ da Constituição da República recepciona os direitos sociais como: "[...] a educação, a saúde, o trabalho, a moradia, o lazer, a segurança, a previdência social, a proteção à maternidade e a infância, a assistência aos desamparados, na forma desta Constituição."

Para tanto, são os destinatários, os cidadãos do Estado, os quais, demandam serviços e políticas públicas. Assim, uma interpretação aberta e pluralista das normas de direitos fundamentais, especialmente, os sociais, é proposta por Harbele, como resultado da participação de todos os destinatários: indivíduos grupos, enfim, além da participação dos entes públicos obrigados a sua garantia e efetivação (HARBELE, 1997, pp. 16-17).

Peter Häberle tratou da influência da interpretação prestada pelos titulares dos direitos " [...] a liberdade religiosa interpretada pelas organizações religiosas, a liberdade artística interpretada pelos artistas, e a liberdade científica interpretada pelos cientista [...]", restando in albis quanto à legitimidade ou à pertinência da interpretação dos indivíduos prejudicados pelo seu exercício (1997, pp. 16-17).

O processo democrático de interpretação daria mais consistência ao resultado, uma vez que envolveria a comunidade, além dos atores formais estabelecidos no processo judicial, ampliando a base de discussão (1997, pp. 43-44), o que se coaduna com o que chamou de "opinião pública democrática e pluralista", como um "catálogo sistemático de intérpretes":

[...] media (imprensa, rádio, televisão, que, em sentido estrito, não são participantes do processo, o jornalismo profissional, de um lado, a expectativa dos leitores, as cartas de leitores, de outro), as iniciativas dos cidadãos, as associações, os partidos políticos fora de seu âmbito de atuação organizada, as igrejas, teatros, editoras, as escolas da comunidade, os pedagogos, as associações de pais (HABELE, 1997, pp. 22-23). 
E por que não incluir a internet, no rol da "esfera pública pluralista", uma vez que constitui local de discussão política, como espaço não formalizado, este contexto do que denominou de esfera pública, constitui modo de subordinação, manifestação e influência sobre decisões jurídicas dos processos. Determinando o grau de democracia, quanto ao controle da formação da opinião pública, advindas do estado ou do setor privado.

O entendimento final, passa pela fixação do conteúdo das normas de direitos fundamentais na esfera pública de discussão como indispensável para democratização da sociedade, voltada para uma interpretação pluralista e aberta da Constituição. Podendo servir para pautar julgamento como meio de se chegar a uma conclusão, ainda mais em se tratando de direitos fundamentais sociais, onde as escolhas são realizadas valorando-se possibilidades além dos requisitos: mínimo existencial, razoabilidade e reserva do possível.

\subsection{A SOCIEDADE ABERTA COMO PARÂMETRO}

Peter Haberle tenciona a análise, expondo que o magistrado não deixa de interpretar levando em consideração a "esfera pública", evidencia-se a questão, ante a necessidade de fundamentação e publicidade das decisões, o que impõe a exposição da decisão, seja de forma técnica, seja pela opinião pública (1997, pp. 26-27).

Ao proferir uma decisão, mesmo em no controle abstrato de constitucionalidade, não haveria uma forma propriamente livre, mas amparado e até sujeito as expectativas ou até mesmo necessidades de certos grupos sociais beneficiados.

Para Haberle a manifestação da opinião pública, ganha influência e legitimidade, posto que, não ameaçam a independência dos magistrados, em que pelo contrário “[...] evitam o livre arbítrio da interpretação judicial” (1997, pp. 32-33).

Vê-se a evidência da opinião pública, sobre conteúdo das normas de direitos fundamentais ainda mais, nos direitos sociais, expõe ao judiciário, muito mais que o congresso, ante a inexistência de meios no nosso sistema para revogação de mandato popular.

\section{Conclusão}

A "sociedade aberta" constitui a base da sociedade brasileira, em que a Constituição da República, estatui direitos individuais, coletivos, fundamentais e sociais, com uma proposta social e liberal ante os fundamentos e objetivos da República Federativa do Brasil;

O Estado de direito constitui o fundamento e o poder político deve ser limitado na Constituição pela Democracia, liberdade de expressão e direitos fundamentais sociais.

A judicialização da política é pretendida como forma de fiscalizar a apli- 
cação Constitucional pelos entes públicos dos direitos fundamentais, especialmente, sociais, uma vez que as políticas públicas constituem mote para o questionamento quanto ao ativismo judicial, entretanto, as diferenças existentes na sociedade e a necessidade de inclusão constituem ponto de partida para a cobrança de políticas e o efetivo atendimento e aplicação dos direitos estabelecidos, ante as desigualdades existentes no Brasil, as quais atingem padrões tão alarmantes.

Peter Haberle definiu os traços fundamentais de uma teoria democrática da interpretação constitucional, direcionada, aqueles que vivem sob a constituição e que para ele também são seus intérpretes.

A Hermenêutica Constitucional de Peter Häberle em "La Imagem del ser Humano dentro del Estado Constitucional" estão intimamente relacionada com o pensamento de Karl Popper, tendo como base a "sociedade aberta".

O racionalismo crítico de Karl Popper, bem como o "faliblismo", demonstram que o ser humano é essencialmente falível, ou seja, o conhecimento por ele produzido não passa de um conjunto de explicações imperfeitas a respeito de uma realidade impossível de abarcar em toda a sua complexidade, necessitando de questionamentos críticos pela comunidade científica.

As "Sociedades abertas", segundo Karl Popper, permitem o diálogo constante, em contraponto as sociedades totalitárias e fechadas, desta forma o processo de democratização da sociedade, passa pela interpretação ou aplicação do texto normativo, em que seria vital para os direitos fundamentais sociais, posto que poderia envolver grupos sociais interessados.

Ao controle judicial de políticas públicas pode ser aplicada uma visão aberta pelo julgador, em que poderiam ser utilizados na interpretação das normas de direitos sociais, a visão dos destinatários específicos e a constatação das pressões sociais, ante as decisões, como componente de legitimação, motivação e coerência. E ainda com a possibilidade de consulta as bases dos destinatários dos direitos sociais, em seu todo: titulares, indivíduos, grupos;

Mediante, a ideia de "sociedade aberta" e "discussão públicas" (Popper e Haberle) estabelece a contextualização do conteúdo dos direitos fundamentais sociais, envolvendo todos os canais da mídia, associações, movimentos, escolas, universidades, igrejas, estações de transporte público, etc., de acordo com cada questão, mitigando assim, o que pode ser considerado "ativismo judicial", adotanto uma postura democrática para o que considera uma nova forma de interpretação.

\section{REFERÊNCIAS}

BUCCI, Maria Paula Dallari. As políticas públicas e o Direito Administrativo. Revista Trimestral de Direito Público, n. 13, São Paulo: Malheiros, 1996.

COURA, Alexandre de Castro. Hermenêutica Jurídica e Jurisdição (IN) Constitucional: Para uma Análise Crítica da "Jurisprudência de Valores" À Luz da teoria 
Discursiva de Habermas. Mandamentos. Belo Horizonte. 2009.

GRINOVER, Ada Pellegrini. O controle de políticas públicas pelo Poder Judiciário. In: O processoEstudos e Pareceres. 2. ed., São Paulo: Editora DPJ, 2009.

HABERMAS, Júrgen. A Inclusão do Outro. Trad. George Sperber, Paulo Astor Soethe e Milton Camargo Mota. São Paulo. Loyola. 2007.

HABERLE, Peter. La Imagem del ser Humano dentro del Estado Constitucional. Fondo Editorial. 2001.

MAUS, Ingeborg. Judiciário Como Superego da Sociedade. Novos Estudos - CEBRAP. São Paulo. 2000.

MOREIRA, Nelson Camatta. Fundamentos de uma Teoria da Constituição Dirigente. Conceito. São José/SC.2010.

POPPER, Karl R. Em Busca de Um Mundo Melhor. Trad. Milton Camargo Mota. Martins Fontes. 2006.

POPPER, Kar R. A Sociedade Aberta e seus Inimigos. Tomo 2 e 3. Trad Milton Amado. Editora Itatiaia, Belo Horizonte. 1998.

ROSENFELD, Michel. A Identidade do Sujeito Constitucional. Belo Horizonte: Mandamentos, 2003.

. Palestra: "Identidade do Sujeito Constitucional e o Estado Democrático de Direito". Simpósio: "Identidade Constitucional e Direitos Sociais”. Tradução e revisão: Fernando Gomes - Transcrição e revisão: Paulo Roberto Magalhães. Cad. Esc. Legisl., Belo Horizonte. jan./jun.2004, v.7, n. 12, pp. 11-63.

SANTOS, Boaventura de Sousa. A Gramática do Tempo para uma nova cultura Política. São Paulo: Cortez, 2006. 